Doutoranda em Letras: Estudos Literários - Universidade Federal do Pará (PPGL/UFPA) Belém Pará - Brasil

\section{MEMÓRIA E TRANSGRESSÃO EMAS CICATRIZES DO AMOR, DE PAULINA CHIZIANE}

Luciana de Barros Ataide
Resumo

onsiderando que a personagem de uma narrativa encena a linguagem, construindo, assim, a verossimilhança que a sustenta, objetiva-se mostrar como o conto "As cicatrizes do amor", de Paulina Chiziane (1994) teatraliza tal processo. Para isso, será problematizado o deslocamento da personagem Maria através de uma abordagem entre a tradição moçambicana e os valores da modernidade no espaço moçambicano, usando, nessa produção, um tom memorialista. $\mathrm{O}$ artigo analisa o processo de construção da personagem Maria destacando como ele, por vezes, chega a confundir o leitor quanto aos limites que separam a ficção da realidade.

Palavras-chave: Personagem. Tradição e memória. Trauma. Literatura moçambicana. Paulina Chiziane.

\section{Introdução}

Paulina Chiziane, escritora moçambicana, nasceu na província de Gaza em 4 de junho de 1955. Filha de uma família protestante, cresceu nos subúrbios da cidade de Maputo. Aprendeu a Língua Portuguesa na escola de uma missão Católica e iniciou os estudos de Linguística na Universidade Eduardo Mondlane, mas nunca concluiu. Paulina, uma contadora de história, iniciou sua atividade literária em 1984 com contos publicados na imprensa moçambicana. São histórias que falam das vivências de tempos difíceis, da esperança, do amor, da mulher e de uma África passada e presente, que a autora soube transferir da oralidade para o papel. Tornou-se a primeira mulher moçambicana a publicar um romance quando lançou o seu primeiro livro, 


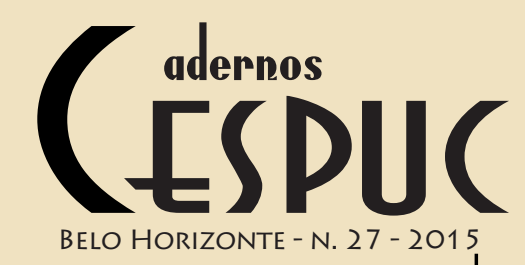

1 Informações retiradas de http:WWW.wikipedia.org/wiki/ paulina_chiziane.

\section{Luciana de Barros Ataide}

intitulado Balada de amor ao vento, em 1990 seguido de Ventos do Apocalipse (1993) e o O sétimo juramento (2000). Com o romance Niketche: Uma História de Poligamia (2002) recebeu o Prémio José Craveirinha (2003). Há ainda $\mathrm{O}$ alegre canto da perdiz (2008), romance no qual aborda o tema do racismo num Moçambique colonial. ${ }^{1}$

O conto "As cicatrizes do amor", de Paulina Chiziane (1994), retrata especificamente Maria, uma personagem que passa por um processo de amadurecimento após a experiência traumática de ser abandonada grávida pelo homem amado e ser expulsa de casa 15 dias após dar à luz sua filha. Com isso, inevitavelmente, é possível ver, através de Maria, como a tradição que estabelece a subserviência feminina pesa como um trauma para a mulher na sociedade moçambicana de origem patriarcal.

Por ser Maria a figura central da narrativa, nota-se que o conto ganha vida a partir de sua trajetória. Isso porque a personagem funciona como o elemento de identificação do leitor com o texto, especialmente por fazer com que o leitor se entregue ao universo ficcional, deixando-se levar pela imaginação. Conforme afirma Rosenfeld, é "[...] a personagem que com mais nitidez torna patente a ficção, e através dela a camada imaginária se adensa e se cristaliza". (ROSENFELD; CÂNDIDO et al. s/d, p. 14).

Para que haja a identificação do leitor com o texto, tanto a personagem quanto o contexto necessitam ser coerentes. Vale então lembrar que imaginação e fantasia em nada se associam à falsidade: personagem é imaginação do autor, é apenas o simulacro. É uma composição feita para o texto ficcional. Renata Pallotini, deixa claro que "[...] o autor reúne e seleciona traços distintivos dos seres humanos, traços que definem e delineiam um ser ficcional, adequados ao propósitos de seu criador". (PALLOTINI, 1989, p. 11). Com isso, percebese que há o jogo construtivo daquilo que o criador pretende mostrar a seu público: os leitores. É importante ainda salientar que é no desenrolar dos acontecimentos que os atos e diálogos da personagem irão esclarecer e dar credibilidade àquilo que é dito pelo narrador da história contada.

A personagem literária 
Para um maior aprofundamento acerca da construção da personagem, faz-se necessário observar primeiramente o conceito de Aristóteles (1997). O pensador define personagem como mimese, como cópia do ser humano. Isso porque, para o autor, a personagem é a imaginação do autor e, quando coerente, é apenas simulacro e é exatamente essa verossimilhança que vai garantir que a obra seja uma obra de arte. É inegável que o narrador funciona como veículo de transmissão da história por meio da narração, mas é a personagem a figura adotada pelo leitor, é nela que o leitor 'encarna' para 'viver' o romance.

Esses seres, que dão credibilidade ao texto, são resultados de uma construção linguística. Eles não existem fora do papel, mas é a eles que o autor dá a voz para expressar a sua visão de mundo. Beth Brait afirma que "a materialidade desses seres só pode ser atingida através de um jogo de linguagem que torne tangível sua presença e sensível os seus movimentos". (BRAIT, 1985, p. 53). Com isso a autora destaca a importância do trabalho linguístico para se criar uma personagem. Ela resume bem essa habilidade linguística quando diz que "A sensibilidade de um escritor, a sua capacidade de enxergar o mundo e pinçar nos seus movimentos a complexidade dos seres que o habitam realizam-se na articulação verbal". (BRAIT, 1985, p. 67).

O conceito da verossimilhança também foi amplamente exemplificado pela autora quando esta afirma que a verossimilhança interna de uma obra pode ser estendida ao conceito de personagem. Contudo, essa afirmação não é por acaso, pois nenhuma personagem se torna verossímil dentro de sua realidade sem o esforço do autor: "Se quisermos saber alguma coisa a respeito de personagens, teremos de encarar frente a frente a construção do texto, a maneira que o autor encontrou para dar forma às suas criaturas, e aí pinçar a independência, a autonomia e a vida desses seres de ficção." (BRAIT, 1985, p. 11).

Com relação à verossimilhança, Anatol Rosenfeld também apresentou suas considerações. Para o autor, a personagem é um ser fictício, mas por ser uma criação da fantasia, comunica a impressão de uma verdade existencial. Nessa verdade é que reside a relação entre o ser vivo e o fictício. Há entre ambos tanto diferença quanto afinidades e nesses aspectos é que está a importância para criar o sentimento de verdade que é a verossimilhança. $\mathrm{O}$ autor esclarece que:

É precisamente o modo pelo qual o autor dirige o nosso "olhar", através de aspetos selecionados de certas 
situações, da aparência física e do comportamento sintomático de certos estados ou processos psíquicos - ou diretamente através de aspectos da intimidade das personagens - tudo isso de tal modo que também as zonas indeterminadas começam a funcionar - é precisamente através de todos esses e de outros recursos que o autor torna a personagem até certo ponto de novo inesgotável e insondável. (ROSENFELD, CÂNDIDO et al., s/d, p. 27 - grifos do autor).

Para Candido (s/d), a definição é mais complexa e múltipla porque o romancista pode combinar os elementos de caracterização, organizados segundo certa lógica de composição que cria a ilusão do ilimitado. Cada traço construído pelo autor adquire sentido de tal modo que a verossimilhança, o sentimento da realidade, depende da organização do contexto. Essa organização é o elemento decisivo da verdade dos seres fictícios, é o que os pode fazer mais atuantes que os próprios seres vivos.

Nesse sentido, independente da abordagem que o autor tome para montar a personagem narrativa, é necessário levar em consideração que a análise perpassa pelo resultado de um trabalho com a linguagem. E ainda mais, independente da opção analítica que será adotada, não se pode perder de vista que se trata de seres puramente intencionais, sendo esta a premissa básica para qualquer estudo de uma obra literária. Isso se deve ao fato de que é exatamente no modo como se organizam e se relacionam os diversos componentes, que o discurso contido apresenta sua visão de mundo, sua ideologia. Isso fica ainda mais evidenciado em Sartre quando diz que "Cada uma de nossas percepções é acompanhada da consciência de que a realidade humana é 'desvendante'; isto quer dizer que através dela 'há' o ser, ou ainda que o homem é o meio pelo qual as coisas se manifestam". (SARTRE, 2004, p.33 - grifos do autor). Logo, é exatamente nesse ponto que reside o contato entre a literatura e a realidade.

\section{A dor do abandono: a memória de Maria}

A escolha do conto "As cicatrizes do amor" deve-se à relevância da narrativa no contexto histórico moçambicano e à situação da mulher nesse contexto, que sempre foi marcada por barreiras sócio-culturais. 


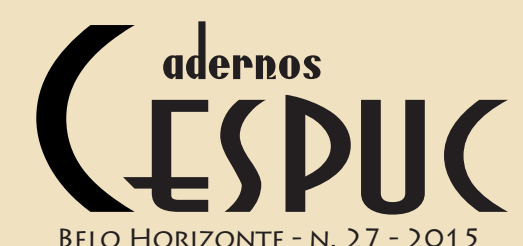

BELO HORIZONTE - N. 27 - 2015

\section{Luciana de Barros Ataide}

No conto será possível observar as lutas e conflitos internos que a mulher carrega, já que serão evidenciados aspectos do quotidiano feminino, a partir das evidências dos signos socioculturais que denunciam o lugar secundário reservado a ela. Isso já pode ser observado logo no início do conto, quando da seguinte passagem: "Diabos me levem se não estou bem nesta roda de mulheres sentadas na areia e os homens nas cadeiras." (CHIZIANE, 1994, p. 128).

Isso mostra que o conto "As cicatrizes do amor" problematiza as relações de gênero e odo papel da mulher na sociedade moçambicana contemporânea através de uma construção social na qual os homens têm um lugar privilegiado se comparado ao da mulher. A eles, são oferecidos desde os melhores lugares à mesa até a oportunidade de ascensão social.

Essas representações sociais acabam por tornarem-se subjetivas na medida em que passam a fazer parte formadora da consciência da população e a fornecerem um modo de viver em sociedade de forma inquestionável. Isso significa que o olhar masculino está acima dos direitos femininos, neutralizando-os, o que favorece a criação de movimentos de identidades fragmentadas quando o assunto é o feminino. O lugar das mulheres submissas consiste na conservação sem ação, sem adequação, já que o outro (o patriarca) impõe o que lhes é permitido fazer.

Sobre a relação dos gêneros existentes em uma sociedade patriarcal, Manuel Castells explica como se dá essa autoridade:

(...) Para que essa autoridade (patriarcal) possa ser exercida, é necessário que o patriarcalismo permeie toda a organização da sociedade, da produção e do consumo à política, à legislação e à cultura. Os relacionamentos interpessoais e, consequentemente, a personalidade, também são marcados pela dominação e violência que têm sua origem na cultura e instituições do patriarcalismo (CASTELLS, 2001, p. 169).

Esse sistema fica bem evidenciado no conto de Paulina, que retrata situações em que as mulheres são apontadas como incapazes de ter um olhar crítico e social para seu universo. Sendo assim, são relegadas de suas próprias vidas. São mulheres silenciadas, sem autonomia ou conhecimento suficiente para fazer a própria história. Assim é o universo vivenciado pela personagem Maria, filha de família tradicional que é obrigada a enfrentar o peso dessa tradição quando é proibida, pelo pai, de casar-se com o homem que amava. Essa proibição faz com que 


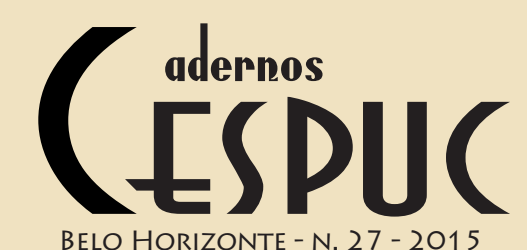

BELO HORIZONTE - N. 27 - 2015

\section{Luciana de Barros Ataide}

Maria seja abandonada por ele estando grávida. Quinze dias depois do nascimento da criança é expulsa de casa. A atitude do pai é o mote que impulsiona a personagem ao mergulho nos costumes do universo de Moçambique através da evocação das tradições e do trauma que as imposições das regras da sociedade trazem.

Dessa forma, mais do que retratar a situação feminina em Moçambique, nota-se que Paulina propõe uma discussão com as negociações transculturais, afinal, a vitalização da presença feminina é imprescindível para a construção do cenário histórico e cultural local. Isso porque a história centra-se na personagem Maria, mulher marcada pelo amor e pelo trauma do abandono. O conto caracteriza-se por um modo lírico de narrar, o que, segundo Inocência Mata (2000), reforça o processo rememorativo. A narrativa tematiza a memória como veículo de revitalização identitária.

No caso de "As cicatrizes do amor", "... uma memória individual se confronta com os ditames de uma sociedade tradicionalista". (MATA, 2000, p. 136). A personagem inicia sua história a partir de uma notícia de jornal, quando a voz de Maria é ouvida como uma forma de denunciar a mulher africana vítima da sociedade, numa narração temporal que focaliza os acontecimentos a partir do passado, através das memórias da personagem: "Alguém folheia um jornal. - Veja isto comadre. Duas crianças abandonadas pelas mães. [...] - O que lhes aconteceu? - Alguém as deitou fora. As mulheres estão doidas." (CHIZIANE, 1994, p. 129).

Através do relato memorialístico, Paulina Chiziane recorre à literatura para mostrar que esta é uma das maneiras de se construir e estabelecer a memória, e também de (re)elaborá-la criticamente. Assim, fica evidenciado o conceito de memória associado à construção feita no presente a partir de vivências ocorridas no passado. Isso pode ser percebido na seguinte passagem: "O vulcão da recordação explodiu narrativas; as lavas caíram como soco nas gargantas abafando os acordes, calem-se todas as bocas, a comadre é que fala! A voz de Maria fez-se ouvir das profundezas do tempo" (CHIZIANE, 1994, p. 129). Essa passagem é início de um momento em que, através do processo de rememoração a personagem Maria reviverá parte da história de sua vida, marcada especialmente pela dor do abandono. Então logo inicia: "Lembro-me da noite sem lua, quando debaixo do cajueiro disse sim, ao homem dos meus sonhos" (CHIZIANE, 1994, p. 130). Nesse momento de 


\section{Luciana de Barros Ataide}

rememoração, Maria inicia o relato de uma vivência.

No contexto do conto de Paulina Chiziane é possível observar que ele, em si, constitui um lugar de memória já que guarda um passado conhecido e encena ambientes de memória ao fazer referência ao ritual tradicional da cultura moçambicana de contar histórias. Isso ocorre no momento em que Maria inicia seu relato e em seu entorno há um grupo de pessoas esperando pela história que será contada; "Vamos, conta-nos tudo, Maria, pareciam incitar as vozes em silêncio" (CHIZIANE, 1994, p. 130). Mais adiante, outra voz de um dos ouvintes é pronunciada: "E depois?" (CHIZIANE, 1994, p. 133). Pierre Nora (1990) define o lugar de memória como a história que ainda possui restos de memória. Logo, é um passado que foi reconhecido e que, portanto, passa a ser arquivado. Quanto aos lugares de memória, Nora define-os seguindo categorias de classificação: “... [há] os lugares topográficos, como os arquivos, as bibliotecas e os museus; lugares monumentais como os cemitérios e arquiteturas; lugares simbólicos como as comemorações, as peregrinações, os aniversários ou os emblemas; lugares funcionais, como os manuais, as autobiografias ou as associações. (NORA apud LE GOF, 1993, p. 473). Com isso, é possível reconhecer que o conto de Paulina Chiziane configura-se como um lugar topográfico de memória, já que registra situações vividas pelas mulheres moçambicanas em determinada época da história de Moçambique. Cabe ressaltar ainda que um dos elementos essenciais que confirmam o caráter social da memória é a linguagem. É pela linguagem que se estabelecem as interações sociais reveladoras das identidades que, por sua vez, remete à oralidade, confirmando assim, a ambientação de memória oferecida no conto.

Com relação à personagem Maria, fica evidenciada a memória silenciada pelo peso traumático da tradição. Uma mulher que não tivera a oportunidade de fazer as escolhas que pudessem guiar a própria vida é obrigada a silenciar-se e aceitar a ordem paterna de abandono do lar. O longo silêncio sobre o passado fê-la resistir ao tempo e ao esquecimento até o momento do desabafo. Sobre a memória silenciada, Michael Pollak diz que “... o silêncio sobre o passado está ligado em primeiro lugar à necessidade de encontrar um modus vivendi com aqueles que, de perto ou de longe, ao menos sob a forma de consentimento tácito, assistiram à sua deportação". (POLLAK, 1989, p. 3). Essa foi exatamente a forma que Maria encontrou para resistir às dificuldades encontradas até ter coragem suficiente para falar da própria história e encontrar um espaço no qual pudesse 
reforçar os laços de pertencimento perdido e compartilhar a memória silenciada. Ao sentir-se pronta para relatar sua situação, é como se Maria tivesse passado por um processo de reconstrução. Sobre isso, Michael Pollak diz que "Através desse trabalho de reconstrução de si mesmo o indivíduo tende a definir seu lugar social e suas relações com os outros". (POLLAK, 1989, p. 11).

A situação vivida por Maria confirma que a constituição da memória de um indivíduo é uma combinação das memórias dos diferentes grupos dos quais ele participa e sofre influência, seja na família, na escola, em um grupo de amigos ou no ambiente de trabalho. Essa memória parece ser retomada no conto quando aparece mais uma personagem que se emociona com o relato de Maria. Isso remete à constatação de que a situação vivida por Maria foi apenas mais uma de tantas outras Marias:

\begin{abstract}
Na caserna de Maria há uma mulher que chora, e os soluços sincronizam com a makwayela das palmeiras. Os corvos em revoadas grasnam agouros, as nuvens já abalaram e o sol voltou a abrasar. As águas do Índico balançam com mais força sob o domínio do vento sul. No coração da noite haverá tempestade. (CHIZIANE, 1994, p. 133).
\end{abstract}

A partir desse acontecimento, a questão do signo é retomada. Signo esse que remete à memória. A cicatriz de Maria, que parece durar a vida inteira, é também percebida em uma mulher que chora na caserna onde todos estão reunidos. Então, esse signo, pela perspectiva de Deleuze (1987) é aquele que faz pensar, aquele que é resgatado pela memória:

O que nos força a pensar é o signo. O signo é objeto de um encontro; mas é precisamente a contingência do encontro que garante a necessidade daquilo que ele faz pensar. $\mathrm{O}$ ato de pensar não decorre de uma simples possibilidade natural; ele é, ao contrário, a única criação verdadeira. A criação é a gênese do ato de pensar no próprio pensamento. (DELEUZE, 1987, p. 96).

A contingência do relato de Maria parece ter sido também vivida por outra(s) mulher(es) dessa sociedade, confirmando a situação de tantas "Marias" daquele espaço de Moçambique e do mundo.

Rupturas: Maria em cena de transgressão 
Em um processo de deslocamento, a personagem Maria "ressignifica" a visão que se tem da mulher dentro de uma sociedade patriarcal moçambicana. Gradativamente, ela modifica a posição da mulher passiva, subserviente e objeto em mulher transformadora. Maria passa do papel da mulher criada para obedecer ao esposo para o de protagonista de sua própria vida. Ela faz a travessia do universo patriarcal e luta contra o destino que lhe tentam impor.

O estereótipo de mulher transgressora desenha a imagem de uma mulher contrária às convenções socioculturais; mulher que luta com toda bravura, mulher forte e audaciosa e firme em seu propósito. Uma mulher que traz no corpo e na alma as marcas do sofrimento e que começa a ser desvendada a partir da cena em que todos estão reunidos bebendo e conversando na "caserna de Maria” (CHIZIANE, 1994, p. 128), local onde ““... o povo triste recria a felicidade" (CHIZIANE, 1994, p. 128). Nesse instante, alguém folheia um jornal e: " - Veja isto, compadre. Duas crianças abandonadas pela mãe.” (CHIZIANE, 1994, p. 129). Imediatamente a voz denunciante retruca: "- Alguém as deitou fora. As mulheres estão doidas.” (CHIZIANE, 1994, p. 128).

Em meio à confusão do que fora noticiado, Maria discorda de seus convidados e pronuncia-se: "- A maldade nasceu antes da humanidade. A culpa cabe às mães, mas é de toda a sociedade." (CHIZIANE, 1994, p. 129). Logo em seguida, Maria é acusada, por uma voz masculina, de estar cometendo um equívoco por culpa da embriaguez: "- Não fuja da verdade, comadre, que a culpa está com as mulheres. O que dizes é suruma de bebedeira, estás embriagada, sim.” (CHIZIANE, 1994, p. 97). À voz masculina, Maria logo revela seu segredo:

- O que vocês não sabem - disse Maria - é que cada nascimento tem uma história e cada acção uma razão. $\mathrm{Na}$ minha juventude cometi o mesmo crime, ou melhor, ia cometê-lo. Tudo por causa desse amor amargura, amor escravatura, que transtorna, que enfeitiça, fazendo da amante a sombra do amado. (CHIZIANE, 1994, p. 97).

Assim, é iniciado o relato da personagem Maria mostrando os processos necessários à reconstrução da condição feminina por meio de uma denúncia às opressões pelas quais passa. Esse episódio do passado rememorado coloca em discussão os 


\section{CESPUC \\ BELO HORIZONTE - N. 27 - 2015}

\section{Luciana de Barros Ataide}

valores da tradição e da modernidade. Ao colocar-se mediante o reviver dessa experiência violenta, mais uma vez o autoritarismo da supremacia masculina fica evidenciado:

Lembro-me da noite sem lua, quando debaixo do cajueiro disse sim, ao homem dos meus sonhos. O régulo de Matutuíne, meu pai, disse não a esse pobre, sem gado para lobolar a filha do rei. Ao meu homem ultrajado não restou outra alternativa senão procurar o lenitivo das mágoas do outro lado da fronteira, em Johannesburg, deixando-me o ventre semeado. Nos nove meses de gesta, minha alma em suplício consumiu facadas. Quinze dias depois do nascimento da criança, o meu pai disse: fora desta casa. (CHIZIANE, 1994, p. 130).

Com isso, nota-se que nem Maria foi dona de seu próprio desejo, nem mesmo a mãe de Maria fora ouvida. Esse silêncio das mulheres representa, por si, a submissão diante da lei.

Contudo, logo depois da expulsão, depois de ser desprezada pelos amigos, Maria se destaca como uma figura determinada que deseja encontrar seu objetivo:

Amarrei a capulana bem firme; com o bebê bem seguro nas costas, jurei: os empecilhos que obstam a minha estrada serão removidos pela minha mão. Chegarei a Johannesburg, minha terra de promissão. Abandonei a casa no ritual dos galos cerrando as cortinas vesperais. Segui o rasto do cruzeiro do sul, caminhei dias, e noites suficientes para contar todas as estrelas do firmamento. (CHIZIANE, 1994, p.130).

Assim, a identidade feminina projetada pela sociedade patriarcal começa a dar lugar à imagem da mulher desafiadora. E Maria segue contando toda a sua dor e sofrimento na busca de seu objetivo, até quando chega o momento em que tenciona abandonar sua filha:

Meus olhos inquietos procuravam uma lixeira, uma vala, uma corrente de água, esgotos, um lugar qualquer, para desfazer-me do meu fardo.

\section{(...)}

De repente o coração pulsou: uma moita cruzou o horizonte dos meus olhos. Será ali, será ali, o cemitério da minha filha, e à noite, bandos de corvos deliciar-se-ão com o corpo frágil do meu rebento, ai!...

Mergulhei na moita, paraíso ilícito. Os amantes 


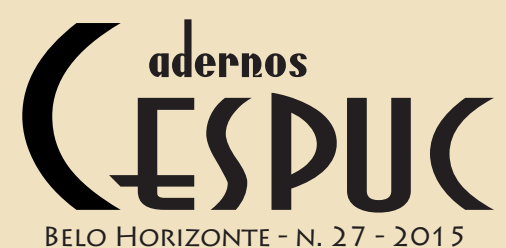

BELO HORIZONTE - N. 27 - 2015

\section{Luciana de Barros Ataide}

também lá estavam, protegendo os abraços dos olhares indiscretos, e eu nem os vi, empenhada que estava na minha tarefa secreta. Adeus, fruto do prazer e dor; amor de fervor, adeus? Abandonava o lugar em passos de fuga; o casal que me espiava lançou gritos, alarmando os transeuntes que me rodearam. Uma velhota enxotou os curiosos, levou-me à sua casa para tratar da criança. Nem com isso desisti de meus intentos.

\section{(...)}

O sono venceu-me. No sonho vi a minha pequena já crescidinha, rindo em gargalhadas rasgadas nos braços do pai. O choro da criança interrompeu o meu sonho, transportando-me para o novo sonho desta vez bem mais real: acriança sorria, vencendo a agonia. (...) Os espíritos do mar venceram o mal, amém? Pelo sinal da Santa Cruz. (CHIZIANE,1994, pp. 131, 132).

Após essa narradora/personagem compartilhar sua trajetória, seus dilemas, suas buscas ela denuncia, através de sua fala, a condição à qual a mulher está submetida e clama por uma nova ordem no que tange à liberdade feminina. Uma saída para essa liberdade é firmarem-se economicamente e libertarem-se do sistema patriarcal. Maria o fez, já que logo no início fica a observação de que todos estavam reunidos na "caserna de Maria”. Essa referência de posse foge ao estatuto social vigente, pois estar à frente de um comércio é uma atitude tipicamente masculina.

Nessa personagem transgressora refletem-se características peculiares: não desanima, amadurece mediante o sofrimento, age valentemente reagindo à violência à qual é submetida, mantém-se firme. Em alguns momentos mostra-se submissa: "Desatas o lenço e a capulana. Da blusa já levantada, espreitam os seios surrados de mil beijos, desfraldas as cortinas de teus segredos [...]" (CHIZIANE, 1994, p. 130). Porém, logo desconstrói essa ideia: "Aprendi a má lição. Antídoto para a vigarice: vigarice e meia [...]". (CHIZIANE, 1994, pp. 132133).

Ao mostrar sua força, sua coragem para driblar os obstáculos sem jamais pensar em desistir de seu propósito, apresenta-se como uma mulher que aprende a sobreviver fora se seu lugar de origem: "Como uma pena voando ao vento, balancei de poiso em poiso, contornando vilas, cidades, até alcançar o objecto da minha aventura: o meu homem". (CHIZIANE, 1994, p. 133). Durante todo o seu processo de peregrinação em busca de seu objetivo, as constantes opressões a impedem de 
adquirir características fixas, pois teve de reagir às demandas impostas, sem, contudo, aceitá-las. Ainda assim, transpõe-se do estereótipo de mulher dependente para a perspicácia de uma heroína.

Dessa forma, no conto "As cicatrizes do amor", Maria, além de articular-se como mulher que se constrói, coloca a narrativa nos polos patriarcal e transgressor. A identidade da personagem articula-se no movimento que vai de um lado a outro, deslocase e transmuta-se no espaço e nesse contexto ela assume-se enquanto sujeito de sua história. Ao conquistar seu projeto e colocar-se como dona de um estabelecimento comercial, uma atitude tipicamente masculina, Maria transpõe a ideia de mulher obediente e passiva para construir-se socialmente.

\section{Considerações}

Ao escrever o conto "As cicatrizes do amor", Paulina Chiziane apresenta, com sua narrativa, elementos essenciais para a compreensão da condição humana, já que trabalha com a verossimilhança. E o faz como forma de reconstruir o ser humano e denunciar suas vicissitudes.

As considerações de Sartre acerca da realidade humana confirmam a função da Literatura, uma vez que um dos principais motivos da criação artística, para o filósofo, é a necessidade que o autor tem de se sentir essencial ao mundo. (SARTRE, 2004, p. 34). Essa necessidade tida pelo autor mostra que o ato de escrever se dá pelo desnudamento do mundo, e, contudo, do homem porque, ao escrever, o autor transfere para a obra certa realidade. Portanto, chega-se a uma ideia de que o ato da escrita exige uma espécie de pacto entre autor e leitor para que ambos possam colaborar na transformação do mundo, da realidade.

Essa realidade é conseguida, por Paulina Chiziane, devido à verossimilhança que a autora transmite ao texto. Seja qual for a análise proposta, o conto contribui para o entendimento do universo feminino do qual a personagem Maria faz parte e que define sua função dentro da narrativa. No conto, a escritora moçambicana, primeira mulher a publicar um romance em seu país, procura demonstrar, a partir do relato da personagem Maria, a condição feminina por meio de uma denúncia às opressões pelas quais passa não só a personagem, mas grande parte das mulheres. Ao mesmo tempo, o conto denuncia a 
condição humana e o grau de violência que ela pode impor à mulher. Essa é entrevista na insensibilidade do pai de Maria ao expulsá-la de casa e também de outras pessoas que negam ajuda a uma mulher com uma criança ao colo.

Em síntese, esse conto retrata o preconceito e suas consequências ao mostrar a mulher sempre responsabilizada e penalizada. Mesmo quando suas ações transcorrem em meio ao desespero, e ainda que confesse a dor do abandono, ou que faça peregrinação ao Sul da África para o encontro com o homem amado, as dificuldades passadas com uma criança recémnascida fez de Maria uma personagem que retrata as mulheres sempre como as responsabilizadas e penalizadas.

\begin{abstract}
Considering that a character of a narrative emulates language, constructing the verisimilitude that sustains it, we intend to show how the short story "As cicatrizes do amor" by Paulina Chiziane (1994) dramatizes such process. For such endeavor, we will analyze the dislocation of the character Maria amongst the aspects of tradition and modernity the the Mozambiquen spatial reality. The article also intends to reflect about the limits of reality and fiction concerning the character.

keywords: Character. Tradition and memory. Trauma. Mozambican literature. Paulina Chiziane.
\end{abstract}

\title{
REFERÊNCIAS
}

ARISTÓTELES. Poética. Tradução, prefácio, introdução, comentários e apêndices de Eudoro de Sousa. Clássicos de Filosofia. Lisboa: Imprensa Nacional/Casa da Moeda, 1997.

BRAIT, Beth. A personagem. São Paulo - Ática, 1985.

CASTELLS, Manuel. O poder da identidade. 3. ed. Tradução de Klauss Brandini Gerhardt. São Paulo: Paz e Terra, 2001. v. 2.

CÂNDIDO, Antônio; ROSENFELD, Anatol; et al. A personagem de ficção. $2^{\mathrm{a}}$ ed. São Paulo: Perspectiva, s/d.

CHIZIANE, Paulina. As cicatrizes do amor. In: ROSÁRIO, Lourenço do e GODINHO, Maria Luíza. (orgs.). O conto moçambicano: da oralidade à escrita. Rio de Janeiro: Te Corá Editora, 1994. 
CESPUC

BELO HORIZONTE - N. 27 - 2015

\section{Luciana de Barros Ataide}

DELEUZE, G. Proust e os signos. 8. ed. Tradução de Antonio Piquet e Roberto Machado. Rio de Janeiro: Forense, 1987.

LE GOFF, Jacques. Memória. In: LE GOFF, Jacques. Memória e História. Campinas: Unicamp, 1990. p. 423- 483.

HALBWACHS, M. A memória coletiva. São Paulo: Vertice, 1990.

MATA, Inocência. Paulina Chiziane: uma coletora de memórias imaginadas. In: Metamorfoses. Lisboa: Edições Cosmos, 2000.

NORA, Pierre. Entre memória e história: a problemática dos lugares, In: Projeto História. São Paulo: PUC, n. 10, pp. 0728, dezembro de 1993.

PALLOTTINI, Renata. Dramaturgia: a construção do personagem. São Paulo: Ática, 1989.

POLLAK, Michael. Memória, esquecimento, silêncio. In: Estudos Históricos, Rio de Janeiro, vol. 2, n. 3, 1989, p. 3-15.

SARTRE, Jean Paul. Que é a literatura. Tradução de Carlos Felipe Moisés. São Paulo: Editora Afiliada., 3ª Edição, 2004. 